\title{
Anxiety: Melanie Klein's 'deeper' layers
}

\author{
R. D. Hinshelwood
}

\begin{abstract}
In Klein's development of a clinical practice with children, she concentrated on the presence and content of anxiety in the little patient's play. This led her away from a basic theory grounded in instincts and energy. As her method developed and her experience accumulated she emphasized the meanings of anxiety and in particular the forms it took in unconscious phantasy. Ultimately, she became aware of profound phantasies, and anxiety, in her patients about the formation and integrity of the ego, and not just the neurotic conflicts the ego struggles with - those anxieties about identity she called the deeper layers of the unconscious.
\end{abstract}

Indeed patients themselves leave us in no doubt here. With few exceptions they one and all complain of some disorder of feeling (Brierley 1937, p. 257).

Klein wrote some autobiographical notes in 1959 and remarked there:

I have often been asked how it was that I tackled the children in the way I did, which was entirely unorthodox and, in many cases, in contrast to the rules laid down for the analysis of adults. I still cannot answer what made me feel that it was anxiety that I should touch and why I proceed in this way, but experience confirmed that I was right and, to some extent, the beginning of my play technique goes back to my first case (Klein 1959, p. 24)

By the time she wrote this, she had recovered from the considerable criticism she had suffered from classical psychoanalysts during the 1940s and 1950s. Her natural selfconfidence seems to be once again coming through. She is a little enigmatic when she says she was 'entirely unorthodox' in deciding she should 'touch' anxiety, but she thought it was against the rules. In fact, looking from a historical distance, as we now do, what she did was to move away from the classical psychoanalytic theory of instincts which Freud had been developing. She turned towards a focus on the expression of an affect - anxiety. She gave anxious relations priority over vicissitudes of the instincts. As Marjorie Brierley (1937) said, our patients start by expressing their anxieties, and so Klein had started by listening to their anxieties.

In addition, Klein was concerned predominantly with children until 1930 or so. And it may be that children are more openly expressive of their experiences, both 
pleasure and suffering. So Klein, as a mother, may have been especially alert to the way children expressed their feelings. Indeed the 'first case' she refers to was probably one of her own children, Erich her youngest (born 1914; see Grosskurth 1986, Frank 2009). Her analyst at the time, Sandor Ferenczi as well as many other analysts in the early years, including Freud and Karl Abraham, were observing young children for the theoretical purpose of confirming the development of the libido Freud had laid out from his work with adult patients.

Klein encouraged each child to express themselves by giving a set of small toys to each of them. So, her 'play technique' was aimed at enabling a free expression that could expose the anxious thoughts in an easily visible way. Anxious children did in fact construct narratives that communicated how they feared certain things. As she concentrated on observing the play, their troubling narratives came into view. She used these narratives as pointers towards the core of their pain. The example of Ruth below showed Klein clearly what the child was anxious about.

Before giving that example, we need to note that Klein claimed it was important to watch any change in the level of anxiety. This was significant because if anxiety reduced after an interpretation, she argued this was evidence of the accuracy of an interpretation. For Klein, anxiety caused inhibition in play; and therefore freer play, less inhibited, indicated relief from a resistance and therefore implied a reduction in anxiety.

One of many examples Klein gave in her papers was Ruth a little girl of $4^{1 / 4}$. Ruth was so anxious and disturbed and suspicious of others, she would not stay in the same room with the strange analyst. Her sister, in her teens, had to stay in the room during the sessions. The sister had commented that the analyst had no hope that Ruth would play with her:

One day while Ruth was once again devoting her attention exclusively to her sister, she drew a picture of a glass tumbler with some small round balls inside and a kind of lid on top. I asked her what the lid was for, but she would not answer me. On her sister repeating the question, she said it was 'to prevent the balls from rolling out'. Before this she had gone through her sister's bag and then shut it tightly 'so that nothing should fall out of it'. She had done the same with 
the purse inside the bag so as to keep the coins safely shut up. Furthermore, the material she was now bringing me had been quite clear even in her previous hours. I now made a venture. I told Ruth that the balls in the tumbler, the bits of money in the purse and the contents of the bag all meant children in her Mummy's inside, and that she wanted to keep them safely shut up so as not to have any more brothers and sisters (Klein 1932, p. 54).

This was quite a deep interpretation, reaching as far as the analyst could into the unconscious feelings of anxiety that disturbed Ruth so much. Here the interpretation is about the anxiety that new brothers and sisters would arrive, and she would feel resentment towards them. Ruth expressed in her play (perhaps unconsciously) her awareness of her need to bottle them up for good. Ruth responded after the interpretation in a way that impressed Klein:

The effect of my interpretation was astonishing. For the first time Ruth turned her attention to me and began to play in a different, less constrained, way (Klein 1932, p. 54).

There was a dramatic change, and Klein took this as evidence of the effect of her interpretation. The new acknowledgement of the analyst indicated a lessening of anxiety and therefore the validity of the interpretation.

Klein had presented this case to demonstrate that speaking about the anxiety in a matter-of-fact way had a dramatic effect. It was not just playing with Ruth that helped to manage the anxiety that disrupted her; the analyst expressed the drama in words and that had astonishing effect. Klein must have felt she had discovered some really important method of demonstrating the anxiety, the resistance to it, and the impact of interpreting it.

This demonstration was of great importance to Klein at the time. In 1927 Anna Freud had criticised Klein's mode of interpreting. Anna Freud had said that children would not be able to understand the point of analysis, and that the first steps need to be simple reassurance, even teaching, in order that the child might begin to understand what the analyst was saying. Because the child would be threatened, the initial steps are difficult and there is not a possibility of a positive transference, which analysts believed then to be the reason patients took their analysis seriously and benefited from it. She 
argued that for children there can be no transference from the primary objects, because those objects are still there on a daily basis.

Klein argued against all these points and defended her own case for making interpretations from the beginning, by presenting cases such as Ruth who clearly responded to her interpretations very differently from the way in which Anna Freud predicted they would. In fact, Klein thought that the child actively tries to engage the analyst in a process of understanding their anxiety demonstrated in the play. Klein's method was supported she thought by the fact that when the child's unconscious communication was listened to and expressed by the analyst, the child was greatly reassured - in a way that was very different from Anna Freud's conscious reassurance.

Their debate was never resolved between them, and even today it resurfaces. In a discussion with Angela Joyce (not a Kleinian), who raised the contrast between simply playing and making interpretation, Irma Brenman Pick (taking the Kleinian position) said:

[W]e enter the domain of the earlier conflict of play versus interpretation between Anna Freud and Melanie Klein, namely, is the analyst required to find a way to draw or seduce the child into treatment, as Anna Freud advocated, or is there a way of reaching the point of the most urgent/maximal anxiety and interpreting from there as Klein said? (Brenman Pick 2011, p. 170-171).

To speak the unspeakable is valid even in children, according to Klein and to child analysts down to the present day.

The contrast is perhaps especially represented by the word seduce used in this quote. It implies some criticism, as, for Brenman Pick, an analysis is about making a meaning, a narrative that captures the anxiety that cannot be managed. In contrast, Anna Freud said there must be a reliance on some actual satisfaction to the patient. Providing actual satisfaction fitted, in the time of Anna Freud, with the instinct theory and the need to satisfy a drive. For Klein it was not about satisfying drives. Rather it was about capturing in words the pain of anxiety which so many analysts at the time thought was a risky business with children.

This fear of risking overwhelming children by exposing libido from behind their defenses, was quite strong in Vienna. We need to remember that in Vienna, one of the 
first female analysts, Hermine Hug-Hellmuth, was murdered by her adopted son, after Hug-Hellmuth had tried to use psychoanalytic thinking in his upbringing (Maclean and Rappen 1991). The murder occurred in late 1924. The incident must have shocked the Viennese Society, and left them very cautious about analysing children.

Klein set out her method of 'early analysis' as one where the deepest anxieties were acknowledged, and indeed were pointed to by the little patients. The removal of the protective defences did seem possible, provided there was an adult person to accompany the child, an analyst who could face the terrible narratives sufficiently to capture them in words.

This approach led Klein to point strongly towards the relevance of phantasy, rather than instinct. It is a conception of the mind as narratives of the relations with objects, rather than the flow of psychic energy. I have been arguing that although Klein herself says she did not know why she took this alternative approach, we can see something of the reasons, deriving (perhaps) from her maternal response to children who were suffering.

\section{Anxiety and instincts}

Klein's choice of anxiety as the focus of interest is an alternative to the starting point of Freud's metapsychology, although it is not altogether clear she was aware of her distinctly different approach. Freud gained his medical education and research experience in the late Nineteenth Century. Vienna was one of the key places at that time when medicine was turning away from the models of the ancients, concerned with humours, and medical scientists began to embrace an approach that copied the physical sciences - in particular physics and chemistry. Instead of treating symptoms, medicine had turned to the investigation of the causes of symptoms residing in the physical processes of the body. Freud's inclination was therefore to found his own 'science' on a similar approach - the underlying causes in the physical processes of the brain.

Gustav Fechner had influenced Freud from student days, and had postulated a physiological equivalent that flowed in the brain/mind. He called it psychophysics in his treatise Elements of Psychophysics in 1860), and Freud took up this theory of psychic energy. Klein was uninfluenced by these sophisticated theories at that time. In 
fact she never used the term 'psychic energy' in her writing, nor 'the economic model'. It was the unconscious phantasy of Oedipus that she saw actually in front of her in the dramas of children's play. Freud wrote his neurophysiological account of neuronal functioning in 1895 (as well as his book on Aphasia in 1891, which had localised certain brain functions). All this was very highly technical, and Freud had been at the forefront of this research. In applying this scientific approach to the underlying causality of neurotic symptoms, he was probably very far ahead of his early colleagues in his Wednesday group. But he was also probably repeatedly challenged by his own patients who were interested in the painful symptoms they suffered, and were much less interested in underlying causes and mechanisms.

In contrast to Freud, Klein developed a clinical approach that was not embedded in this culture of scientific medicine. Her initial encounter with psychoanalysis was in Budapest. One could say she started from an unfortunately naive position without any scientific understanding of biological instincts. On the other hand one could say she had the advantage of being unencumbered by the academic and professional pressures for the technical proficiency that shaped Freud's thinking. Klein had not trained as a doctor or scientist. In fact, she did not have a University education, in an age when women rarely did. She was not exposed to the ideas that Freud absorbed in the mid- to late Nineteenth Century. Though all her childhood and schooling was in Vienna, she was denied the opportunity to go further though she had wished to be a doctor. She was strongly influenced by her elder brother, Emanuel, who Melanie, as youngest in the family of four children, idolized. Emmanuel had a passion for education and he wished also to be a doctor, but he also wrote poetry. When he died young of tuberculosis, in Genoa, Melanie was quite bereft. She rescued his possessions, found his poems, and published a book of them. A number of her papers are on literary and artistic themes, including her late paper on the Oresteia.

One might say her literary interest emerged in her concentration on the narrative focus of her play technique. Klein established it as the notion of unconscious phantasy which Kleinians have later emphasized. She could be said to have taken this aspect of Freud's theories, his Oedipus complex, as a model for conceptualizing all experience. 


\section{The importance of narratives of relations}

The detailed narrative from Ruth's analysis given above is an example of the focus in Kleinian thought on narrative phantasies. Another such example is the even younger girl, Rita, aged 23/4 years, who suffered already from severe obsessional symptoms, and demonstrated very explicitly her narratives of the battles that caused her anxiety, and panic attacks. Klein wrote:

After a ceremonial which was plainly obsessional, her doll was tucked up to go to sleep and an elephant was placed by the doll's bed. The idea was that the elephant should prevent the 'child' from getting up; otherwise the latter would steal into its parent's bedroom and either do them some harm or take something away from them (Klein 1929, p. 136).

The child was playing out an idea that something in her would do some harm to her own parents. Even at her age, this caused an impulse to stop herself:

The elephant (a father-imago) was to act the part of a person who prevents. In Rita's mind her father, by a process of introjection, already filled this rôle, ever since, at the time she was a year and a quarter to two years old, she had wished to usurp her mother's place with him, to steal away the child with which her mother was pregnant and to injure and castrate both parents. The reactions of rage and anxiety which took place when the 'child' was punished in these games showed that in her own mind Rita was enacting both parts: that of the authorities who inflicted punishment and that of the child who received it (Klein 1929, p. 136).

The child was torn between wanting to commit some harmful act of violence or theft, and at the same time wanting to prevent herself. The drama is very explicit, though concrete, about the child's anxiety about the damage it could do. She both loved and protected her parents, and she also wanted to harm them. Here is a narrative of love and hate played out in very explicit detail.

Around 1930 Klein became a training analyst of the British Society. There exist some notes in the archives, of her clinical observations around 1934 with adult patients (Hinshelwood 2006). I was struck by her approach which seemed to be reminiscent of her play technique. She did not use toys of course. But she conceptualised the patients as managing their ideas and experiences in their minds as a child might play with actual 
toys. It seemed a replication of phantasies of objects in relation to each other that tell similar threatening stories. It was as if she transferred her method of observing the narratives of children's play, to the narratives of an adult's thinking processes. To illustrate this briefly, here is a short passage from her notes of an adult patient's verbal presentation:

St.... feels continuously hindered in his work by the anxiety that if he has got a good thought it would be taken away by the enemies inside him, who would only interfere when it is worthwhile. So the anxiety increases if it is a good thought. Associations of going up a mountain, leading sheep while he has to control enemies which follow on and which he has to control continuously so that they should not disturb the sheep. Then he might still fall back from the top if he meets an enemy, but could be helped if he meets a friend (published in Hinshelwood 2006, p. 31).

The thoughts are 'played' with as if they were toys. Some 'good' thought is threatened as in Rita's anxious play, by the interaction of bad ones. The 'play room' was as it were internal. The internal space of his mind seemed to be where his unconscious phantasies were played out.

This appears to be a distinct divergence from a classical approach to observing free associations clinically. It seems almost certain that Klein did not understand the theories of instincts that Freud had developed in his Three Essays on Sexuality (1905), and the papers on metapsychology (of 1914-5). She had herself had analysis with Sandor Ferenczi over some years during World War I, and we know that Ferenczi emphasized the personal relationship. In the 1920s, that attention to the intimacy of the analytic relationship began to set him apart from Freud. This may have coincided with Klein's own developing emphasis (Likierman 2001). Ferenczi appears to have prioritized an intimacy with his patients and their suffering rather than the scientific investigation of underlying scientific causality which Freud thought was needed. And Klein may have shared that more empathic orientation with Ferenczi.

Freud was not entirely consistent, I would claim, and he had a bivalence and could be read both ways, as a material scientist, and as a humane empathic listener. In his first great work, which he always went back to, was his discovery of the meanings in 
dreams and the painful anxieties which have to be hidden by indulging in wishes and phantasies to obtain a spurious and transitory wish-fulfilment. As time went on, it appears the scientific psychologist came to the fore in his writings.

\section{Anxiety and affects}

Although anxiety appears to be the single basic affect in both Freud's and Klein's views, they see anxiety arising in two different ways. For Freud, anxiety was an experiential consequence of the fate of psychic energy, specifically when it was blocked (a tension phenomenon, Freud 1909, p. 244). Later however, instead of being a direct result of a defensive blocking of a drive, anxiety was described as a warning sign of a danger arising potentially from some situation in reality; i.e. a signal-anxiety aroused by these dangersituations (Freud 1926). For Klein this latter view of anxiety as a signal was nearer the mark. For her anxiety was the cause of defences, rather than the result of the blocking of instinctual energy. So, whereas Freud's signal anxiety implied some warning of an external situation, Klein's view of anxiety was about an internal situation that promised danger, perhaps danger to the external world.

In the examples she gave in general, and in the two given here, the anxiety emerged as the consequence of imagined interactions between the toy figures. Klein decided that those figures must, ultimately, represent the key figures in the mind of the child. In the first example here, Ruth needed to protect herself and others against the rage she would have to deal with if mother conceived a new baby. And Rita seemed very explicit that the danger she had to prevent was her anxiety about the parents in their own bedroom excluding Rita. Anxiety for Klein was an anxiety about feelings, about what happens to love. Rita loved her parents and wanted to protect them. She had to protect them from her own enraged reaction arising from her exclusion from the parents' night-time relationship. It is a quite different origin of anxiety from Freud's.

Thus, anxiety is a feeling about feelings, a sort of second-order feeling. It seems therefore to have a reflexive quality. Freud, over the years, eventually postulated a second form of anxiety, and this he called guilt (Freud 1917, 1923). Guilt too has a self- 
reflective quality which comes from the self-observing function of the ego. Both affects warn of trouble from the emotions brewing within the self. Though Klein's views parallel Freud in the categorization of anxiety and guilt, Klein's conceptualization, on the basis of narratives about objects (including the self as one of the objects in the narratives), led her to two different formulations:

- A fear for the self (or persecutory anxiety); and

- A fear for the other (or depressive anxiety).

As is well known, Klein elaborated these two kinds of anxieties in terms of 'positions': the paranoid-schizoid position, and the depressive position. Each position has characteristic object relations, anxieties and defenses against the specific anxiety.

Late in her career, Klein (1946) published her investigation of the paranoidschizoid defences. However, there is evidence in the archives that she was looking at this much earlier, and the brief note on 'St' above comes from those archives in 1934 (Hinshelwood 2006). At this point there is an interesting convergence with some of her critics from the classical position of ego-psychology. Klein showed from her work in the 1930 s that she was interested in the weakness of the ego, and the psychodynamic forces which cause it. There is therefore a shared interest in the ego's weaknesses and the ego's difficulties in managing itself and its experiences. Although there is a different conception of how such weaknesses come about, the integrity of the ego and control of its impulses is a common interest.

In Klein's terms the ego loses its coherence due to processes of self-disintegration which seriously weaken it. However, Freud himself began the examination of how the ego can lose its coherence, first with his paper on 'Group Psychology and the Analysis of the Ego' (Freud 1921), and then in his description of the splitting of the ego into two non-communicating parts in his paper 'On Fetishism' (Freud 1927, as well as his posthumous and unfinished paper on splitting of the ego in 1940). This theme of the integrity of the ego, or its lack, became important in British object-relations psychoanalysis (Glover 1943, Winnicott 45). Klein (1946) described her own views on the processes of disintegration and defenses against it. The fear of disintegration - she called it 'annihilation' - is the core anxiety of the paranoid-schizoid position; it is persecutory anxiety. It provokes a whole range of specific defenses which she believed 
were not reducible to repression, and in some sense lay 'beneath' that neurotic level based on repression. There was, she frequently said, a 'deeper' layer of the unconscious.

For her the loss of integration, or splitting, and these specific defenses which she called the schizoid defenses were implicated in the more serious mental illnesses. Perhaps rashly, she called them the psychotic defenses, although she thought they were apparent in the very early stages of normal development prior to about six months of age. And in that connection, she called the anxiety of disintegration or annihilation, 'psychotic' anxiety. Subsequent to 1946, there was some considerable evidence of these schizoid mechanisms and the anxiety of disintegration in severely disturbed people with schizophrenia (Rosenfeld 1947, 1965, Segal 1950, Bion 1957, 1959). Klein thought that the anxiety about the coherence and existence of the self/ego was a very primitive one and that it underlay the anxieties of the Oedipus complex. In effect it is a 'self'psychology, a psychology of the self. As Bion put it:

The non-psychotic personality was concerned with a neurotic problem, that is to say a problem that centred on the resolution of a conflict of ideas and emotions to which the operation of the ego had given rise. But the psychotic personality was concerned with the problem of repair of the ego (Bion 1957, p. 272).

You have to have a coherent, functioning ego first, in order to have conflicts in it and to resolve them. Thus, anxiety about the survival of one's self is the earliest anxiety, and as she said located in the deeper layer of the unconscious.

\section{The deeper layers and container-contained}

This view of the nature of anxiety, developed from Klein's theory of the schizoid mechanisms, had evolved after her death into an important and now widely acknowledged model of technique. As Klein had demonstrated, if the analyst listens in to the patient's fearful narratives, and can accompany, as it were, the journey to understand, then there can be a real change in the anxiety. That view is today understood as 'containment'. It represents a form of extraneous and auxiliary egostrength, which is available for the patient to internalise as an added function for himself. This process is seen as operating in both the analytic dyad and in the mother- 
infant couple. It is an interactive process between the intra-psychic dynamics of both of the partners.

If the patient, like an infant, cannot manage a particular anxiety, then the accompanying other is required to take on that anxiety together from the patient. Moreover, this process is seen as operating in both the analytic dyad and in the motherinfant couple. There is a real transmission - or communication - in which one of the two passes an anxiety into the other. At an unconscious level, the aim is that some other ego can give the anxiety some meaning. That meaning shall then be delivered back as the same anxiety but in some manageable and meaningful form. In the analytic setting, that manageable form is a conscious verbal form - although a mother cannot use verbal meanings with her pre-verbal infant and must use messages via her behaviour and responses.

This is a process of handing back and forth a state of anxiety. Freud (1921) had described this movement of something of the ego from one to another. He had acknowledged LeBon's (1895) term 'contagion'. At that time Freud was also in communication with Karl Abraham who was using the more technical psychological terms 'projection' and 'introjection' for this transmission between minds. But Abraham was clear they were felt in narrative form, as a story about the handing over of some experience, and indeed some part of the ego. Klein took this from Abraham and understood the way the ego can move its states around interpersonally, either actually or in omnipotent phantasy. A definitive Kleinian version of this kind of transmission was given by Heimann (1952).

Klein's descriptions showed how these splitting defensive processes could enhance the disintegration of the ego, that is, in the act of trying to protect the ego from the anxiety of annihilation the ego can become more disintegrated. Some persons get trapped in this destructive cycle and lapse into actual psychotic states. The ego then becomes fragmented and evacuated, a process known as projective identification, and in such a psychotic state the person feels frighteningly surrounded by bits and pieces of destroyed ego.

However, Kleinians (Money-Kyrle 1956, Bion 1959, Segal 1978) subsequently recognized that this psychotic process could have the more 'normal' function of a non- 
verbal communication. It would be a communication by moving anxiety around between minds in the process of containing as just described. This less radically destructive psychotic function then became known as a communicative projective identification. For instance:

The child projects into the breast unbearable feelings. The mother elaborates them and if she gives an appropriate response, the child can introject the breast as a container capable of dealing with feelings. The introjection of such a container is the necessary precondition for the elaboration of the depressive position (Segal 1978, p. 317).

This puts the process in the terms of the mother-infant relationship and the early egodevelopment. The infant develops into the depressive position by the strengthening of its ability to withstand the anxiety that has previously promoted splitting. Now the assistance of the mother allows the infant to contain his own anxiety a bit more. However, she continued:

But a great deal can go wrong in the projection. The relation between the container and the contained may be felt as mutually destructive or mutually emptying, as well as being mutually creative (Segal 1978, p. 317).

These difficulties arise either because the infant is hampered in using the mother adequately, or because mother is not in fact able to manage the anxieties the infant needs to dump into her. Nevertheless, in most instances, the infant gains enough meaning from mother to achieve the 'meaning-making' process for him/herself.

This mother-infant developmental process has now become a model for the analytic process itself - even in adult analyses. The process is meaning-making in this sense through the passing of anxiety back and forth. In the analytic setting, that modification of the anxiety into a more manageable form is through the creation of conscious verbal forms that express the meaning for patients. And again, difficulties may arise; either because the patient has difficulty in using the analyst's function of accepting and modifying - a negative therapeutic reaction, in effect. Or it may be because the analyst has his own difficulties in accepting the specific anxieties the patient needs him to hold and modify. 
This is a model of a developmental analytic process which is convincing to many. In summary, the patient projects the urgent anxiety, and the analyst introjects it. The analyst then makes some meaning of it, using both words and some of the stock of meanings from his psychoanalytic training and experience. Then this newly managed anxiety, together with the method of giving it a manageable meaning, is relocated back into the patient's mind. Of course, much can go wrong, and the steps by which it does falter are also helpful in understanding what has happened in stuck analyses and situations of impasse.

Description of the analyst's side of this emotional transaction brings us, in effect, to a consideration of the countertransference. The analyst has to perform the job not just of identifying appropriate theories, but, much more importantly, and with more difficulty, he has to identify his own emotional state and try to recognise what feelings are his own, what belong, as it were, to the patient (Money-Kyrle, 1956, Brenman Pick 1985), and what gets mixed up between them. And also it is of importance that whatever the troubling problems of the analyst that may lead to his fumbling with the patient's projections, the analyst has also to take account of the use the patient may make of the analyst's limitations. The analyst's job is as much emotional as intellectual.

Klein's theories of anxiety have given others wide scope to understand states of the ego and its inadequacies, relevant to the contemporary demand for the important work with quite severe disorders of personalities.

Moreover, this process of the container-contained is a model of listening which can be applied to all human encounters. The process just described may easily be seen as that which underlies the ordinary intimacy of friends confiding their unhappinesses to each other. It points, in fact, to the special nature of human communication in which typically something of one person goes inside another. In regard to this penetrative process, the forms of linkages between human beings were generalised in a notation used by Bion (1962), when he used the Mars-Venus symbol; $\sigma^{\prime \prime} \circ$. These represent of course the penetrative intercourse between men and women but were used as a general symbol of all relations and links between people, though he was quite aware he was adhering all the time to Freud's Oedipus configuration. 


\section{Conclusions}

In this paper, I have tried to put in as simple a language as possible Melanie Klein's theory of anxiety, its degree of divergence from Freud's, and the way it has been developed into a model for therapeutic work.

Klein felt that her approach was not just close to patients' experiences, as shown in children's play and later in adults verbal descriptions of their minds, but she thought that it opened new territories to investigation. Just as in science in general, a new method of investigation leads to new discoveries, so Klein thought that her understanding of the kinds of anxiety led to the discovery of this deeper layer of schizoid mechanisms, and the problems that beset minds in a psychotic state.

It is possible to see more clearly perhaps that the psychoanalytic task is one in which we try to understand and put into a clear perspective the patient's own narrative of his experiences, and not only the analyst's.

(C)2021 R.D. Hinshelwood

\section{References}

Bion, W. R. (1959) Attacks on linking, International Journal of Psychoanalysis, 40, 308-315. Reprinted in Bion, W.R. (1967) Second Thoughts. New York: Jason Aronson; pp. 93-109.

Bion, W. R. (1962) Learning from Experience. London: Heinemann.

Brenman Pick, I. (1985) Working through in the countertransference. International Journal of PsychoAnalysis 66: 157-166. Republished in Elizabeth Spillius (ed) (1988) Melanie Klein Today: Volume 2, Mainly Practice:: pp.34-47. London: Tavistock

Brierley, M. (1937). Affects in theory and practice. International Journal of Psycho-Analysis 18: 256-268.

Frank, C. (2009) Melanie Klein in Berlin. London: Routledge.

Freud, A. (1927) Einführung in die Technik der Kinderanalyse. Vienna: Internationaler psychoanalytischer Verlag. Published in English (1928) as Introduction to the Technique of Child Analysis. New York: Nervous and Mental Disease Publishing Company. And (1946) as parts I and II of The Psycho-Analytic Treatment of Children. London: Imago.

Freud, S. (1891, English translation 1953) On Aphasia. New York: International Universities Press. 
Freud, S. (1895 [1950]) Project for a Scientific Psychology. The Standard Edition of the Complete Psychological Works of Sigmund Freud, Volume 1: 281-391. London: Hogarth.

Freud, S. (1905) Three Essays on the Theory of Sexuality. Standard Edition of the Complete Psychological works of Sigmund Freud, Volume 7: 125-245. London: Hogarth.

Freud, S. (1909) Notes Upon a Case of Obsessional Neurosis. The Standard Edition of the Complete Psychological Works of Sigmund Freud, Volume 10: 125-245. London: Hogarth.

Freud, S. (1917) Mourning and Melancholia. Standard Edition of the Complete Psychological works of Sigmund Freud, Volume 14: 239-258. London: Hogarth.

Freud, S. (1921) Group Psychology and the Analysis of the Ego. Standard Edition of the Complete Psychological works of Sigmund Freud, Volume 18: 67-143. London: Hogarth.

Freud, S. (1923) The Ego and the Id. Standard Edition of the Complete Psychological Works of Sigmund Freud. Volume 19: 12-66. London: Hogarth.

Freud, S. (1926) Inhibitions, Symptoms and Anxiety. The Standard Edition of the Complete Psychological Works of Sigmund Freud, Volume 20: 75-176. London: Hogarth.

Freud, S. (1927). Fetishism. The Standard Edition of the Complete Psychological Works of Sigmund Freud, Volume 21: 147-158. London: Hogarth.

Glover, E. (1943) The Concept of dissociation. International Journal of Psycho-Analysis 24:7-13

Grosskurth, P. (1986) Melanie Klein: Her World and her Work. London: Hodder and Stoughton.

Heimann, P. (1952) Certain functions of projection and introjection in early infancy.. In Melanie Klein, Paula Heimann, Susan Isaacs and Joan Riviere (Eds.) Developments in Psychoanalysis. London: Hogarth.

Hinshelwood, R.D. (2006) Melanie Klein and repression: An examination of some unpublished notes of 1934. Psychoanalysis and History 8: 5-42.

Klein, M. (1929) Personification in the play of children. The Writings of Melanie Klein, Volume 1: Love, Guilt and Reparation. London Hogarth.

Klein, M. (1932) The Psycho-Analysis of Children. London: Hogarth. Republished as The Psychoanalysis of Children. The Writings of Melanie Klein, Volume 2. London: Hogarth.

Klein, M. (1934) Early repression mechanisms. Wellcome Library archive, PP/KLE B89, Box 17, B89. Published in Hinshelwood, R.D. (2006) Melanie Klein and repression: An examination of some unpublished notes of 1934. Psychoanalysis and History 8: 5-42.

Klein, M. (1946) Notes on some schizoid mechanisms', International Journal of Psycho-Analysis 27: 99110. Republished (1975) in The Writings of Melanie Klein, Volume 3, Envy and Gratitude, pp. 124. London: Hogarth.

Klein, M. (1959) Autobiography - Melanie Klein [1959] Wellcome Library Archive PP/RMK/E.6/3: Box 11: 1-27.

LeBon's (1895) Psychologie des foules. Paris: Alcan. English translation, (1995) as The Crowd. Brunswick (US) and London (UK): Transaction Publishers. 
Likierman, M. (2001) Melanie Klein: Her Work in Context. London: Continuum.

MacLean, G. and Rappen, U (1991) Hermine Hug-Hellmuth. London: Routledge.

Money-Kyrle, R. (1956) Normal counter-transference and some of its deviations. International Journal of Psychoanalysis 37: 360-366. Republished 1978 in The Collected Papers of Roger MoneyKyrle. Perthshire: Clunie Press. And republished in Elizabeth Spillius 1988 Melanie Klein Today, Volume 2. London: Routledge.

Pick, I.B. (2011) Discussion of "Interpretation and Play". Psychoanalytic Study of the Child 65: 169-174.

Segal, H. (1978) On Symbolism. International Journal of Psycho-Analysis 59: 315-319.

Winnicott, D. (1945). Primitive emotional development. International Journal of Psycho-Analysis 26:137-143. 